Engineering, Technology and Tecniques

Vol.61: e18160767, 2018

http://dx.doi.org/10.1590/1678-4324-2018160767

ISSN 1678-4324 Online Edition

AN INTERNATIONAL JOURNAL

\title{
Investigation on Solar PV generation and design of switched reluctance motor for Smart Agriculture actuation system
}

\author{
Murali Muniraj ${ }^{1 *}$, Arulmozhiyal R. ${ }^{1}$

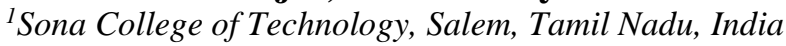

\begin{abstract}
This paper presents standalone solar photovoltaic $(P V)$ powered fed actuation system employing a switched reluctance motor (SRM) particularly used in remote and rural areas. The converter efficiency is achieved by changing $O N$ and OFF state of solar PV drive. An electronic commutation drives SRM drive with achieved by position hall sensor and encoder. The modified boost converter is proposed in single stage to conversion of $P V$ fed power and inverter with reduced switching losses. Further proposed system is designed to reduce cost of system using simple design and control. This paper also proposes the speed control strategy of SRM motor with an artificial intelligent based Adaptive neuro fuzzy inference (ANFIS) system to achieve desired motor velocity as stated in reference velocity in farm lands. The system proposed is subjected to analysis the performance of drive and controller in both load and no-load conditions. Initially, a simulation model is modeled in MATLABSIMULINK with corresponding environments. The experimental setup for proposed system is developed using FPGA based SPEEDGOAT real time target machine. The simulation and hardware results suggest feasibility of proposed system in real time.
\end{abstract}

Keywords: SRM drive, ANFIS, Modified boost converter, PV, actuation, MATLAB-SIMULINK, SPEED GOAT,

\footnotetext{
*Author for correspondence: muralimunraj@gmail.com
} 


\section{INTRODUCTION}

Agriculture is a backbone of each and every country development. As the water scarcity is arises day by day, water for irrigation farming reduced. It is necessary to develop a scientific system based solution which will reduce time in process of farming. As water transportation and delivery for rural and remote areas lacks for farming is lacks due inefficient power supply to consumer. Water pumps and hand pumps represents a conventional water supply methods for minimum water access. In particular water pumps is designed to operate with maximum energy from grid. Enormous disturbance to grid in rural areas leads to lack of electricity supply leads to lack of irrigation in specified remote areas $\left[^{1}\right]$. In India recent grid failure which made the people to live in darkness and instability towards to human needs. Economic growth gets damages heavily and standstill of development in industrial sectors during grid failure. Renewable based energy is booming day by day and dependency on grid reduces in recent years. Renewable energy assures green and clean power sources and prices of PV panels and wind constructional equipments decrease due development in material based research. As PV panels are easily placed and increase of rooftop solar $\mathrm{PV}$ in every homes reduces power quality issues and return fed to power grid.

The major drawbacks in renewable is instability of delivering power, it essential to design a modeling power processing unit to deliver a constant power to loads. Research in this field will further reduce the cost and complexity in the solar generating system and in near future, the dependence on fossil fuel for power generation will be reduced ${ }^{2}, 3$. Renewable based power generation with power processing unit leads the significant reduction of cost of solar panels in the recent years have made the small industries to set up their own micro power generation unit for industrial needs ${ }^{4}$.

$\mathrm{PV}$ power generation is processed by power electronics unit to improve input power for which a boost DC to DC converter is used traditionally. Many converters has been analyzed in literature survey, each converter has their own limitation such as reliability, efficiency and operating mode of system. MPPT control technique limits input efficiency and abortive to deliver major impacts for solar and wind energy systems 5 . Here a modified boost converter is proposed with single stage conversion techniques which drive PV power directly fed to inverter drive system of actuation system $^{6}$. The proposed modified boost converter reduces the threshold voltages and reduces size of inductor and implements capacitive based converter maintains stability to deliver constant dc-link voltage ${ }^{7}$.

Actuation system plays major in many applications like automation in industries, actuator in defence sector, position control in medical field. Conventional Dc motor are widely used a few ago, Brushless DC motor(BLDC) and SRM motor ideal choice for actuation systems which provide wide speed range ${ }^{8}$. BLDC is being used in many applications due to limitations such as complex control, low reliability; further demagnetization irreversible occurs in permanent magnet BLDC motor. In spite of variable losses in BLDC motor, SRM motor with controller drive makes an ultimate preference which has simple construction and high torque density ${ }^{9,10}$.

The major requirements of SRM motor drive states better dynamic and steady state response, robustness and low torque ripples. At present proportional, integral, derivative controller is being widely used in many applications ${ }^{11,}{ }^{12}$. In recent intelligent neuro techniques are being proposed to deliver better performance and responds to system behavior ${ }^{13}$. Fuzzy and neuro are two advanced control techniques which process as human system intelligent behaves effectively for mathematical nonlinear system ${ }^{14}$. Fuzzy and neuro control techniques has their own advantages and disadvantages, in the proposed controller a neural network trained the input and output of nonlinear function and fuzzy rules are formed linguistic variables. 
In this paper, modified boost converter fed solar PV to drive SRM motor actuation system corresponding advantages listed in Table 1 and overview is as shown in Figure 1. By proposing ANFIS controller the number of fuzzy sets is reduced and input is trained using artificial neuro networks with improved stability and system performance. The rules are formed through practical behaviour of SRM motor drive. The speed error and rate of change of error is calculated to implant gains values of controller. A SPEEDGOAT real time FPGA board provides I/O interfaces and host the ANFIS control algorithm developed in MATLAB, Further simulated and compiled system into FPGA controller I/O boards to test proposed algorithm with modified boost converter fed solar powered SRM motor drive.

This paper is organized as follows. Section II introduces the Solar PV system and SRM motor drive system architecture. The modelling of intelligent controller fuzzy and ANFIS with control structure and design procedure is illustrated in Section III in detail. Simulation of proposed system and corresponding results in MATLABSIMULINK environment is presented in Section IV. Experimental results and comparisons and validations of proposed controller and converter for SRM motor drive is detailed in Section V. Section VI concludes this paper.

Table 1. Overview of Conventional and proposed system

\begin{tabular}{lll}
\hline Scheme & Conventional 2 stage Converter & Proposed system \\
\hline SRM drive requirements & 3-Hall and 3 current sensor & 4 Position hall sensor \\
Boost Converter & Multiple stage PV conversation (high & $\begin{array}{l}\text { Single stage PV conversion with } \\
\text { less switching looses }\end{array}$ \\
Efficiency & Switching looses) & High \\
Control Strategy & Low & ANFIS control \\
Losses & Conventional and Fuzzy & Low with minimum torque \\
& High with maximum torque & Ripples \\
\hline
\end{tabular}

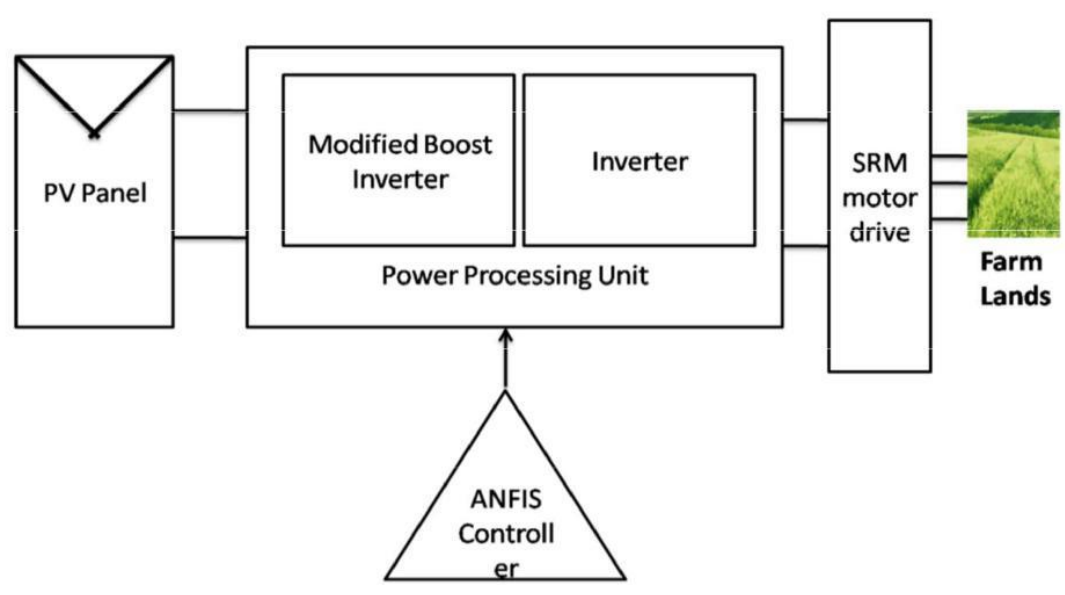

Figure 1. Solar PV fed SRM motor drive with ANFIS controller

\section{PHOTOVOLTAIC SYSTEM}

Photo voltaic system is modelled with photodiode and considered in ideal condition (without losses) and practical condition. PV system with diode is connected in antiparallel when light generated from current source forms module as represented equivalent circuit (Figure 2). The developed module of PV is connected in parallel or in series to achieve required voltage and current. The characteristics of this PV cell can be obtained using basic current of the circuits is in equation 1 . 
$\mathrm{I}=\mathrm{I}_{\mathrm{PV}}-\mathrm{I}_{0}\left[\mathrm{e}\left\{\mathrm{V}+\frac{\mathrm{R}_{\mathrm{S}} \mathrm{I}}{\mathrm{V}_{\mathrm{ta}}}\right\}-1\right]-\left(\mathrm{V}+\mathrm{R}_{\mathrm{S}} \mathrm{I} / \mathrm{R}_{\mathrm{P}}\right)$

Where $I_{p v}=$ photovoltaic current, $I_{0}=$ saturation current, $V_{t}=N_{s} k T / q$, the thermal voltage of the array, $N_{s}=$ cell connected in series, $T=$ temperature of the $p-n$ junction, $k=$ Boltzmann constant, $q=$ electron charge, $R_{s}=$ equivalent series resistance of the array, $\mathrm{R}_{\mathrm{p}}=$ equivalent parallel resistance of the array, $\mathrm{a}=$ diode ideality constant.

The series resistance $R_{s}$ are regulated with the value of shunt resistance $R_{p}$, A small change in series resistance can affect more on the efficiency of a PV cells but variation in shunt resistance does not affect more as shown in figure 3 IV charters tics of SPV. For very small leakage current to ground, shunt resistance assumed to be infinity and can be treated as open. The temperature is also significant feature in generation of current in the solar cell which was proved by the following equation.

$I_{P V}=\left\lceil I_{P V} \cdot n+K_{1} \Delta T\right\rceil\left(G / G_{n}\right)$

Where $\mathrm{I}_{\mathrm{pv}}=$ light generated current at the nominal condition $\left(25^{\circ} \mathrm{C}\right.$ and $\left.\mathrm{W} / \mathrm{m}^{2}\right), \Delta \mathrm{T}=\mathrm{T}-\mathrm{Tn}, \mathrm{T}=$ actual temperature $[\mathrm{K}], \mathrm{T}_{\mathrm{n}}=$ nominal temperature $[\mathrm{K}], \mathrm{K}_{\mathrm{I}}=$ current coefficients, $\mathrm{G}=$ irradiation of the device surface $\left[\mathrm{W} / \mathrm{m}^{2}\right], \mathrm{G}_{\mathrm{n}}=$ nominal irradiation. The main parameters of a solar panel are listed in the table 2 . This experimental result suggests equation will determine PV characteristics.

$\mathbf{I}_{\mathbf{L}}$

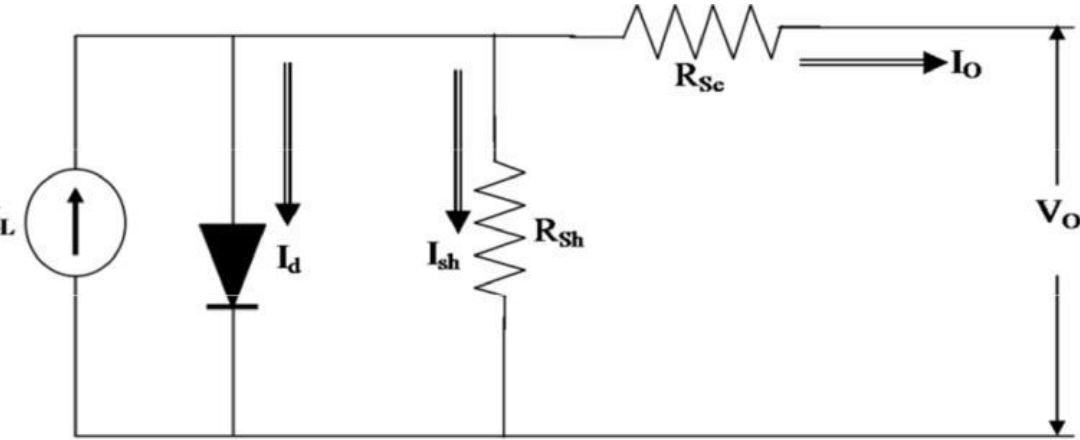

Figure 2. Equivalent circuit of PV module

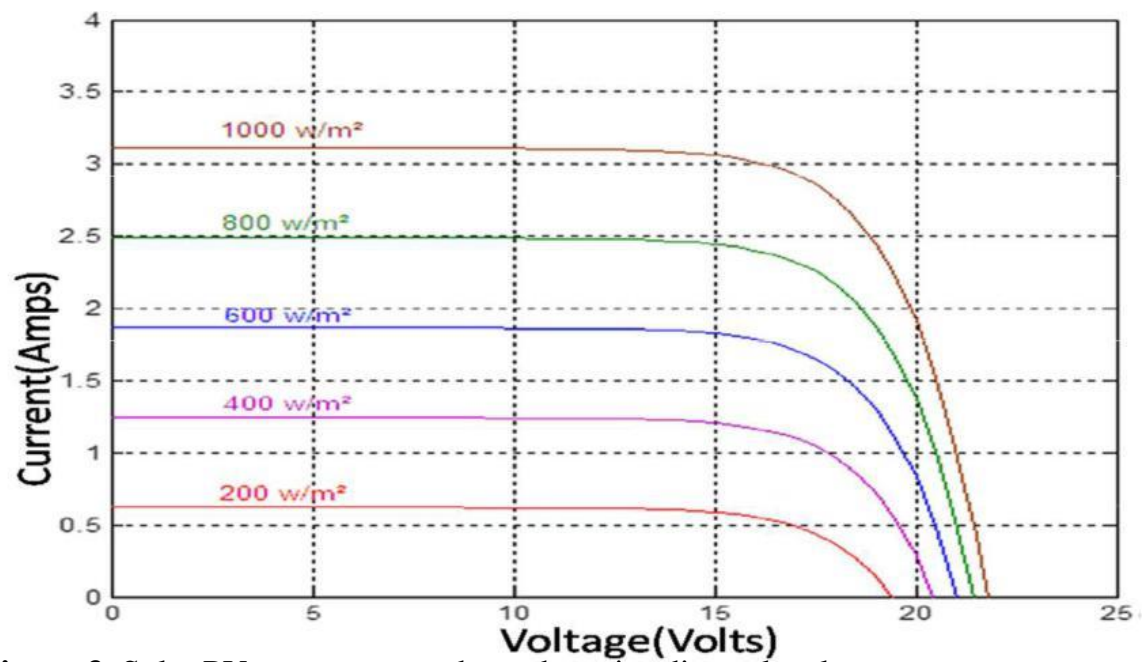

Figure 3. Solar PV output power depends on irradiance level 
Table 2. Parameters of a solar panel

\begin{tabular}{|l|l|}
\hline \multicolumn{1}{|c|}{ Electrical Characteristic } & \multicolumn{1}{c|}{ SLP020-24U } \\
\hline Product code & 020012401 \\
\hline Maximum power (Pmax) & $20 \mathrm{~W}$ \\
\hline Voltage at Pmax (Vmp) & $34.4 \mathrm{~V}$ \\
\hline Current at Pmax (Imp) & $0.58^{\mathrm{a}}$ \\
\hline Open -circuit voltage (Voc) & $43.2 \mathrm{~V}$ \\
\hline Short-circuit current (Isc) & $0.63^{\mathrm{a}}$ \\
\hline Temperature coefficient of Voc & $-(80 \pm 10) \mathrm{mV} /{ }^{0} \mathrm{C}$ \\
\hline Temperature coefficient of Isc & $(0.065 \pm 0.015) \% /{ }^{0} \mathrm{C}$ \\
\hline Temperature coefficient of power & $-(0.5 \pm 0.05) \% /{ }^{\circ} \mathrm{C}$ \\
\hline NOCT (Air $20^{\circ} \mathrm{C}$; Sun $0.8 \mathrm{~kW} / \mathrm{m}^{2}$ wind $\left.1 \mathrm{~m} / \mathrm{s}\right)$ & $47 \pm 2^{0} \mathrm{C}$ \\
\hline Maximum system voltage & $1000 \mathrm{~V} \mathrm{DC}$ \\
\hline Power tolerance & $\pm 10 \% /-5 \%$ \\
\hline
\end{tabular}

\section{Modified boost Converter}

The modified boost dc-dc converter is modeled in such a way operates in continuous conduction mode with minimum numbers of switches. The peak and RMS current of modified boost converter is designed to be low losses during switching and reduce leakage current in inductor while discharging. Here, Insulated gate bipolar transistor (IGBT) switch and corresponding design equation for dc output voltage and input voltage is given $(1-2)$

$$
D=1-\frac{V_{\text {in }}}{V_{O}}
$$

Where $\mathrm{V}_{\text {in }}=$ input voltage of the modified boost converter which is equal to output of the photovoltaic array. $\mathrm{V}_{\mathrm{o}}=$ output voltage of the modified boost converter. Insulated Gate Bipolar switch (IGBT) SW is turned on at $t=0$ as shown in Figure 4.

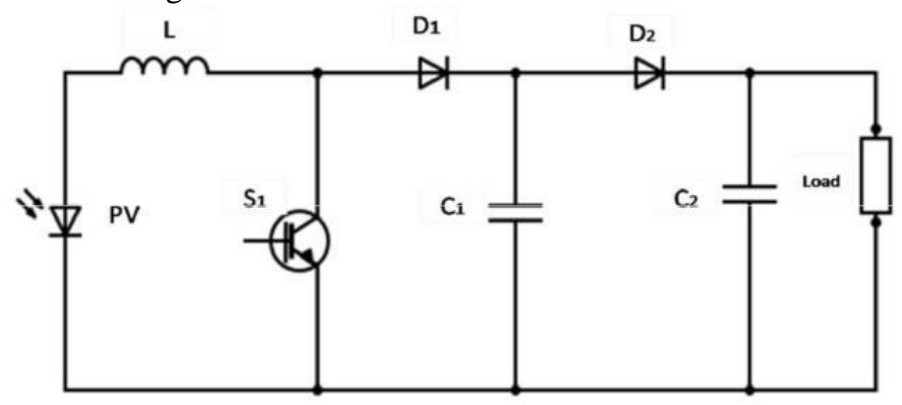

Figure 4. Modified Boost converter

They continuous operation is performed with modified boost converter, Due to inductor L1 input rises and switch (S1) is turn on as switching sequence drawn in figure 5. During the turn off mode of Sw current flowing through inductor (L1) and diode (D1 \&D2) fed to output. The inductor current during switch is turned on and off as a cycle, further energy stored in capacitor fed to load with input voltage. 


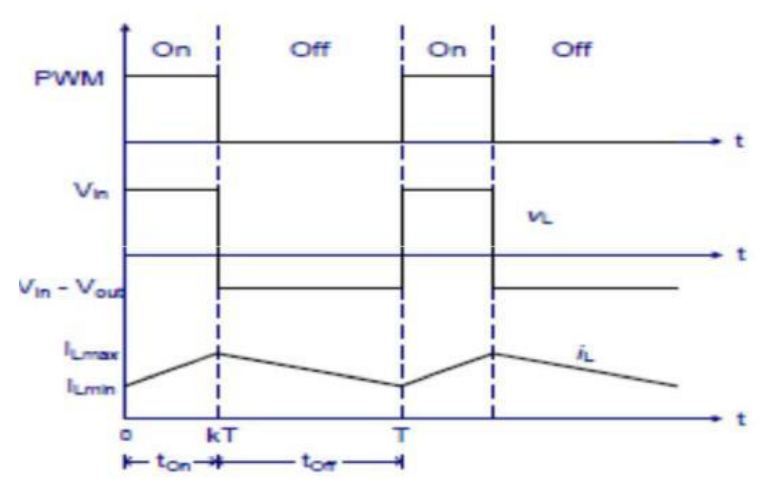

Figure 5. Switching waveforms for Switch sw

The value of the inductor $(\mathrm{L})$ can be given as

$\mathrm{L}_{1} \frac{\mathrm{DV}_{\mathrm{mpp}}}{\mathrm{f}_{\mathrm{SW}} \Delta \mathrm{I}_{\mathrm{L} 1}}=\frac{0.52 * 187.2}{20000 * 18.16 * 0.006}=45 * 10^{-3} \approx 5 \mathrm{Mh}$

Whereas $f_{s w}$ is the switching frequency which is taken as $20 \mathrm{kHz}$ and Io is the load current. The value of input indictor is selected less than value of critical value. $\Delta \#_{\$}$ is allowed current ripple taken from $60 \%$ of Vc and voltage appearing across the indictor $\mathrm{I}_{1}$.

The values of capacitors intermediate vale of $\mathrm{C}_{1}$ and $\mathrm{C}_{2}$ calculated with duty ratio and is given as:

$\mathrm{C}_{1,2}=\frac{\mathrm{DI}_{\mathrm{dc}}}{\mathrm{f}_{\mathrm{sw}} \mathrm{V}_{\mathrm{C} 1, \mathrm{C} 2}}$

$\mathrm{V}_{\mathrm{cl}}$ is voltage across capacitor and Idc average dc current of Dc to Dc gain converter

\section{Design and modeling of SRM drive}

SRM motor is an electrodynamics and electromagnetic equipment operates similar to reluctance stepping motor, where SRM is operated to run continuously which requires position sensor information of rotor. In SRM motor winding inductance, torque and Back EMF depends on the rotor angle and nonlinear angular positioning parameters, while magnetic saturation is the main reason for nonlinear magnetic characteristics ${ }^{13}$. The voltage across the motor phases.

$V_{j}=R i_{j}+\frac{d \lambda_{j}\left(\theta, i_{j}\right)}{d t}+\frac{d \lambda_{i}}{d t}$

Where $\mathrm{Vj}$, stands for the $\mathrm{jth}$ phase winding voltage, $\mathrm{ij}$ for the $\mathrm{jth}$ phase current, $\mathrm{j}$ for the linking flux, $\mathrm{R}$ for the ohmic resistance of the phase winding and $h$, for the leakage linking flux. The linking coupling between adjacent windings has been neglected.

$V_{J}=R i_{j}+\frac{d \lambda_{j}\left(\theta, i_{j}\right)}{d t} \cdot \frac{d i_{j}}{d t}+\frac{d \lambda_{j}\left(\theta, i_{j}\right)}{d \theta} \cdot \frac{d \theta}{d t}+\frac{d \lambda_{i}}{d t}$

Where an, $\frac{d \lambda\left(\theta, i_{j}\right)}{d t}$ is the increasing inductance (Linc) and $\frac{d \lambda_{j}\left(\theta, i_{j}\right)}{d \theta}$ is the back EMF coefficient (Cw), both of which are dependent on current and rotor angular position.

Considering $\mathrm{L}_{\mathrm{k}}$ as the flux leakage:

$\frac{d \lambda_{i}}{d t}=L_{k} \frac{d i_{j}}{d t}$ 
The rotor mechanical kinetic equation can be listed under the function of electromagnetic torque.

The torque is given by:

$T_{e}=\frac{1}{2} i^{2} \frac{d L(\theta, i)}{d \theta}$

Under the simplifying assumption of magnetic linearity the total torque equation becomes:

$T_{T}=\sum \frac{1}{2} i^{2} \frac{d L(\theta, i)}{d \theta}$

Where $\mathrm{T}$ is the instantaneous torque, $\mathrm{L}$ is the inductance of the motor, $\theta$ is the rotor position angle.

\section{DESIGN OF FEEDBACK CONTROLLERS}

The feedback controller measuring the controlled actual speed with reference speed variable to generate controlled variable to influence system performance. Adaptive Neuro-Fuzzy Inference System controller to drive SRM motor as actuator, ANFIS control algorithm with c-dump converter feeds current pulses to drive the SRM operated through the electronic hall sensor commutation. The modeling of fuzzy and ANFIS controller is discussed.

\section{Fuzzy Logic Controller}

Fuzzy controller, interface of input and output, control rules, execute institution and sensors, which actually translates the knowledge and experience of expert into the control law. The actual instantaneous output voltage is sensed, sampled and compared with sinusoidal reference value to create the error voltage. Discrete error voltage $E(k)$ and its change of error $E c(k)$ are processed by the FC rules as listed in Table 3 through fuzzification, fuzzy inference and defuzzification operations. The change of control signal $u(k)$ as the output variable of primary FC is added to the control signal, $U(k)$ to give a updated value of switching angles to compensate properly with any loading variation.

In the FC system, weight factor $K e, K c$ and scaling factor $K u$ relates to the static and dynamic performance. The effect of the gain settings for a conventional PID controller in a closed loop system is related to the scaling factors adjustment in the FC, which can be approximated as actual PI controller.

$$
\Delta u(k)=K_{P} \Delta e(k)+K_{I} e(k)
$$

Referring to FC presented in ${ }^{14}$

$$
K_{U} \Delta u(k)=K_{C} E c(k)+K_{E} E(k)
$$

Relating (2) and (3),

$$
K_{P} \equiv \frac{K_{C}}{K_{U}} \text { and } K_{I} \equiv \frac{K_{E}}{K_{U}}
$$


Referring to conventional PI control experience, the following conclusions can be gained:

- A higher value of Ke will cause a long transition progress or even an overshoot. On the contrary, a smaller Ke will result in a poor dynamic response and a large system error.

- Increscent Kc can make the controller sensitive, which will avoid overshoot of the system output and bring out a slow dynamics. Otherwise, a large overshoot or even a surge will occur.

- The value of Ku will influence directly the output scale of controller. By reducing $\mathrm{Ku}$, a steady output can be achieved. On the other hand, a large Ku makes for a proper dynamics. A compromise should be carried when selecting an appropriate $\mathrm{Ku}$.

Table 3. Primary Fc rules

\begin{tabular}{|c|l|l|l|l|l|l|l|}
\hline EC/E & NB & NM & NS & O & PS & PM & PB \\
\hline NB & NB & NB & NB & NB & NM & NS & ZE \\
\hline NM & NB & NB & NB & NM & NS & ZE & PS \\
\hline NS & NB & NB & NM & NS & ZE & PS & PM \\
\hline ZE & NB & NM & NS & ZE & PS & PM & PB \\
\hline PS & NM & NS & ZE & PS & PM & PB & PB \\
\hline PM & NS & ZE & PS & PM & PB & PB & PB \\
\hline PB & ZE & PS & PM & PB & PB & PB & PB \\
\hline
\end{tabular}

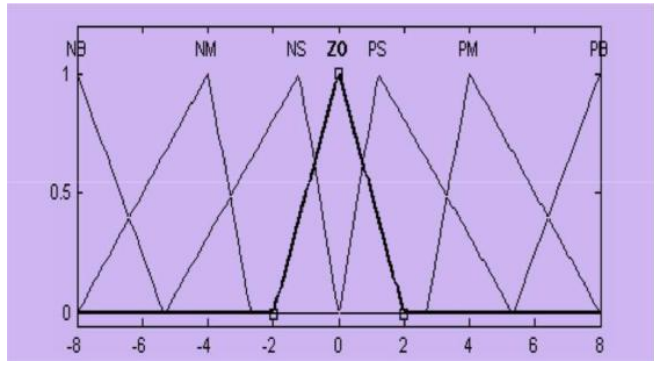

(a) Membership functions of $E$ and $E C$

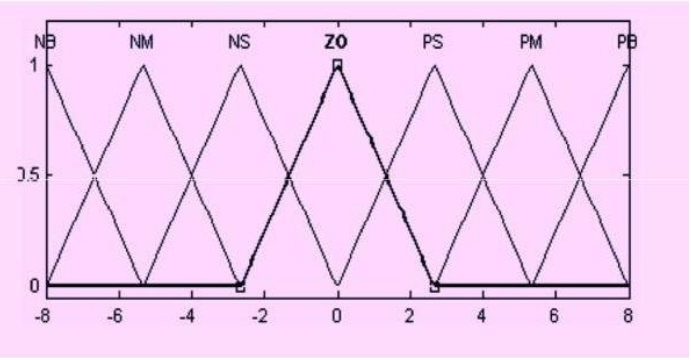

(b) Membership function of $u$

Figure 5. Shape of membership functions for SAFC

As shown in Figure 5, their membership functions have the same geometry of asymmetric Triangle. $u$ as the output variation of primary fuzzy controller is also divided into seven subsets, which is not like $\alpha$, the output of assistant fuzzy controller. $\alpha$ is divided into seven fuzzy subsets from [0,1], \{VS, S, SM, M, BM, B, VB\}. But they have the same membership functions of symmetrical triangle. The inference logic of MAX-MIN method is employed in two fuzzy controllers, similarly the defuzzification method of centroid formula is shown in (4) .

$u=\frac{\sum_{i=1}^{n} \mu\left(u_{i}\right) \times u_{i}}{\sum_{i=1}^{n} \mu\left(u_{i}\right)}$ 


\begin{abstract}
ANFIS Controller
ANFIS is a sophisticated hybrid network developed with neuro and fuzzy network advantage of less time consumption and error percentage. The training network, reverse and forward pass which propagate the network layer and error is sent back propagation. Initially in specified input and output data for training rules for ANFIS network. The command functions in order to train and performs with five layer of state.

Using training data, ANFIS constructs a fuzzy inference system whose membership functions parameters are tuned using either a back propagation algorithm alone, or in combination with recursive least squares type algorithm. Using hybrid learning technique, the learning process speeds up compared to the gradient method alone, which exhibits the tendency to be trapped in local minima. The fuzzy inference system under consideration has two inputs $x$ and $y$ and one output $z$. the rule base contains two fuzzy if - then rules of Takagi and Sugeno's type].
\end{abstract}

Rule 1: If $x$ is $A 1$ and $y$ is $B 1$ then $f 1=p 1 x+q 1 y+r 1$

Rule 2: If $x$ is $A 2$ and $y$ is $B 2$ then $f 2=p 2 x+q 2 y+r 2$

The node functions in the same layer are of the same function family as described below:

- Layer 1: The degree of input satisfies the linguistic label associated with the node and thus output layer of node.

- Layer 2: This node is known as the Rule node, denoted by T. It calculates the firing strength of the associated rule. The output of the neuron can be calculated by:

$\alpha_{1}=L_{1} a_{1} * L_{2} a_{2} * L_{3} a_{3}, \alpha_{2}=H_{1} a_{1} * H_{2} a_{2} * L_{3} a_{3}, \alpha_{3}=H_{1} a_{1} * H_{2} a_{2} * H_{3} a_{3}$

- Layer 3: The process of normalization is taking place in this each and every node, denoted by $\mathrm{N}$ and its output is given by:

$\beta_{1}=\frac{\alpha_{1}}{\alpha_{1}+\alpha_{2}+\alpha_{3}}$

$\beta_{2}=\frac{\alpha_{2}}{\alpha_{1}+\alpha_{2}+\alpha_{3}}$

$\beta_{3}=\frac{\alpha_{3}}{\alpha_{1}+\alpha_{2}+\alpha_{3}}$

- Layer 4: This layer is called defuzzification layer and generally categorized as "then" part and its output is the product of normalization level and the individual rule output.

$\beta_{1} Z_{1}=\beta_{1} V B^{-1} \cdot \alpha_{1}, \beta_{2} Z_{2}=\beta_{2} B^{-1} \cdot \alpha_{2}, \beta_{3} Z_{3}=\beta_{3} S^{-1} \cdot \alpha_{3}$

- Layer 5: The overall output $\left(\mathrm{Z}_{0}\right)$ of the system is computed in this single node as the sum of all the incoming signals. 
$Z_{0}=\beta_{1} Z_{1}+\beta_{2} Z_{2}+\beta_{3} Z_{3}$

This then is how, typically, the input vector is fed through the network layer by layer and considers how the ANFIS learns the premise and consequent parameters for the membership functions and the rules. The corresponding functions is implemented in MATLAB with iteration test data, surface viewer and structure as shown in figure 6 .
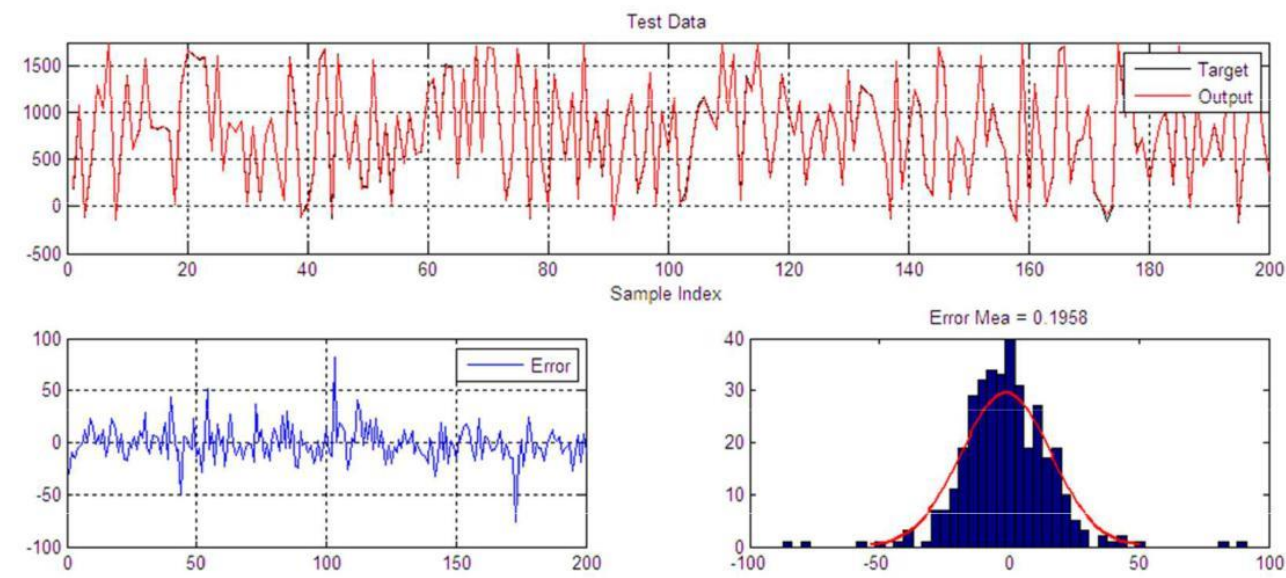

(a)

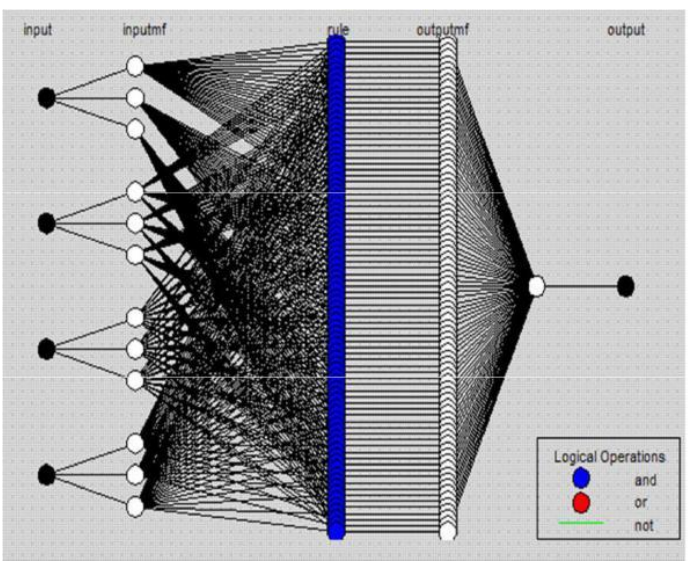

(b)

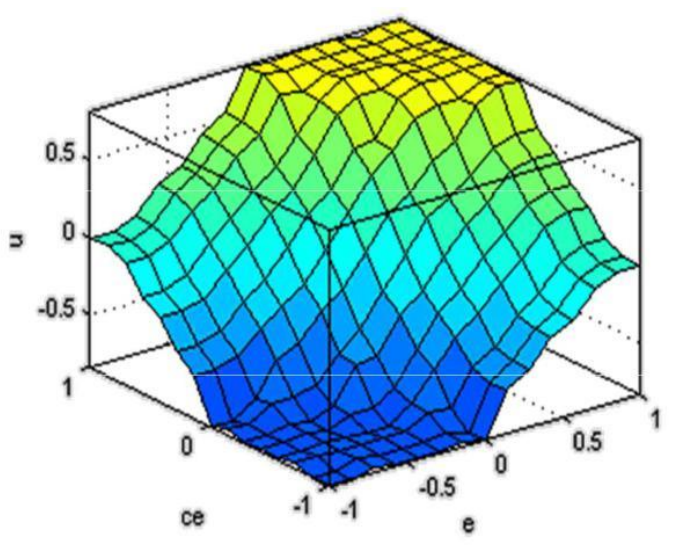

(c)

Figure 6. Results of ANFIS structure and surface viewer

\section{SIMULATION RESULTS}

ANFIS controller is used in the solar powered fed SRM motor to simulate performance of proposed control actuation system. Simulation is implemented in MATLAB-SIMULINK to improve performance of SRM motor drive, ANFIS algorithm is realized in speed control of SRM for smart farm irrigation applications. The simulation model of proposed system with ANFIS control is shown in figure.7. Solar PV system generates maximum voltage for irradiance level of $1000 \mathrm{~W} / \mathrm{m}^{2}$ fed as input to modified boost converter generates delivers constant input supply to SRM motor. The ANFIS controller drives the inverter module by appropriate generation of PWM pulses with corresponding sensors information. 


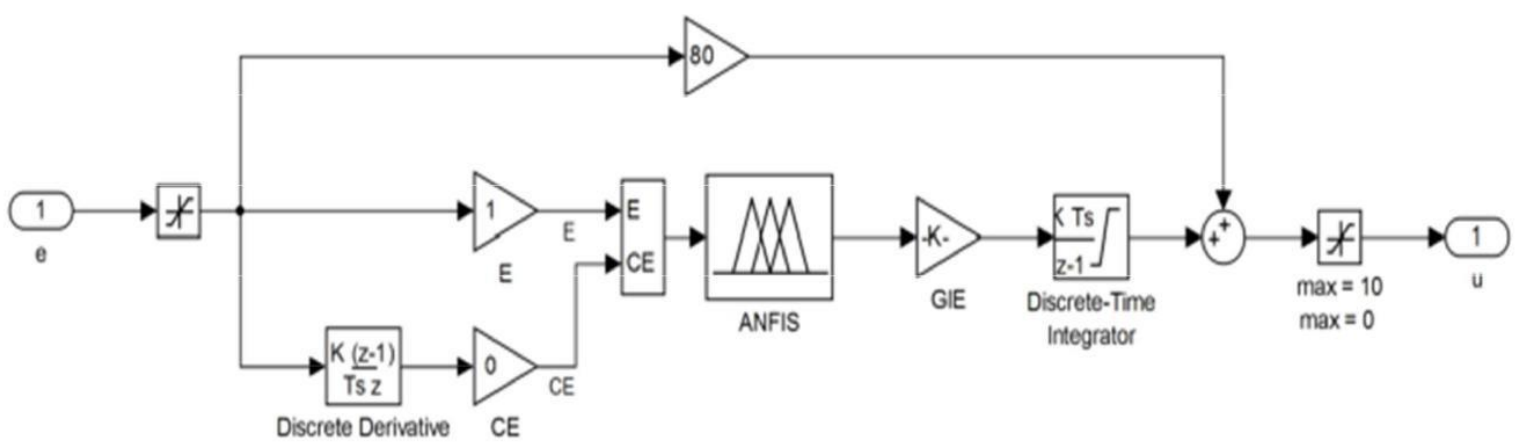

Figure 7. Simulation model of ANFIS controller

\section{Simulation of Photo-Voltaic System}

The solar PV module input is modeled in MATLAB-SIMSCAPE and proposed in this paper. The input signal is converted by PS-SIMULINK converter. It convert the input physical signal to a unit less SIMULINK output signal and fed into drive system for boosting input voltage. The unit expression in output signal unit parameter must match or be commentate with the unit of the physical signal and determines the conversion from the physical Signal to the unit-less SIMULINK output signal. Output is fed to the inerter unit and temperature is set to $25^{\circ} \mathrm{C}$. The irradiation of PV was set to $1000 \mathrm{~W} / \mathrm{m}^{2}$ and corresponding model and output voltage is shown in fig.8 \&9. Several test performance is carried by varying PV irradiance level to verify stability of proposed system.

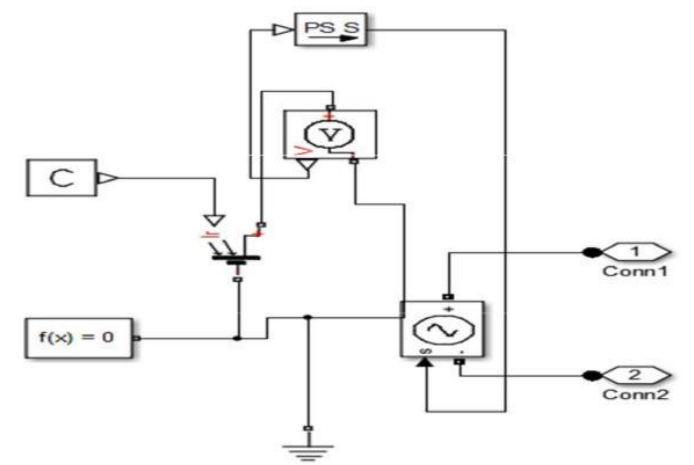

Figure 8. Solar PV module in MATLAB SIMULINK
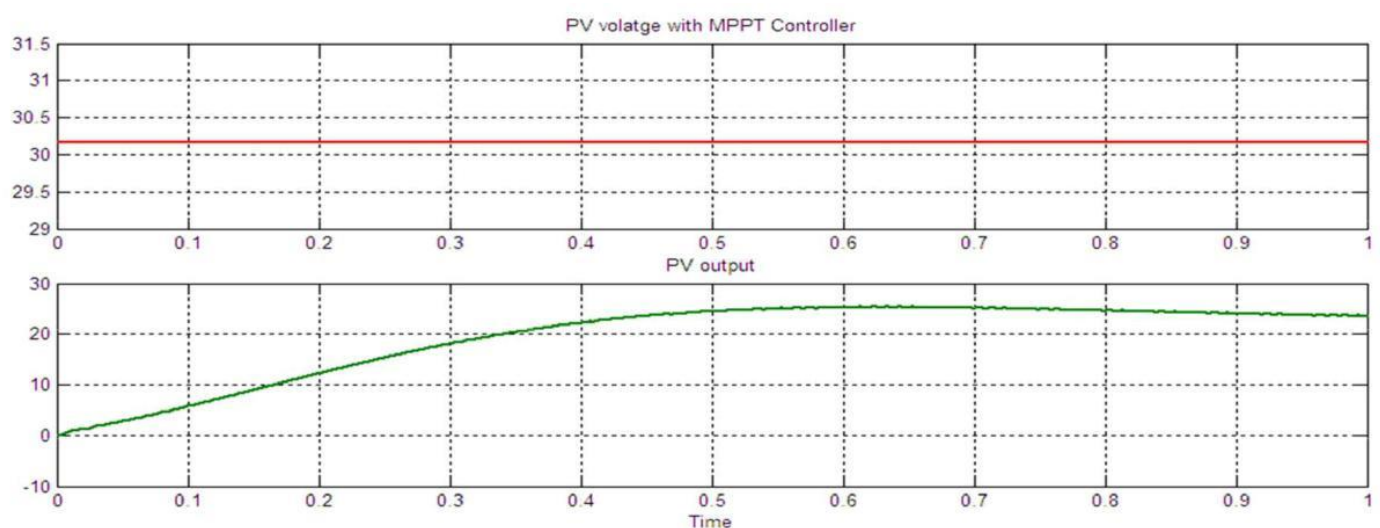

Figure 9. Output voltage of Solar PV module

\section{Simulation of SRM drive System}


Simulation is based on $8 / 6$ switched reluctance motor is analyzed with ANFIS controller. To import the performance of ANFIS controller algorithm in SRM motor, modeling is imposed in MATLAB-SIMULINK environment. The output result of the SIMULINK model of the switched reluctance motor with ANFIS controller as shown in Fig.10. The current in each phase, output torque, inductance of each phase and motor speed parameters performance are shown. Various test results are performed using ANFIS controller and the performances of speed and torque are obtained with respect to time is shown in fig. 11 . In simulation the reference speed of the motor is set and the actual speed of the motor are obtained from the position sensor during starting motor draws current and limited to the maximum value. The actual speed and reference speed are compared and the error will be obtained. The error occurs Neuro fuzzy controller becomes active; likewise the actual speed and reference speed of the motor equal there is no error. During starting current is peak and its peak value reduces when the motor speed reaches its reference value.

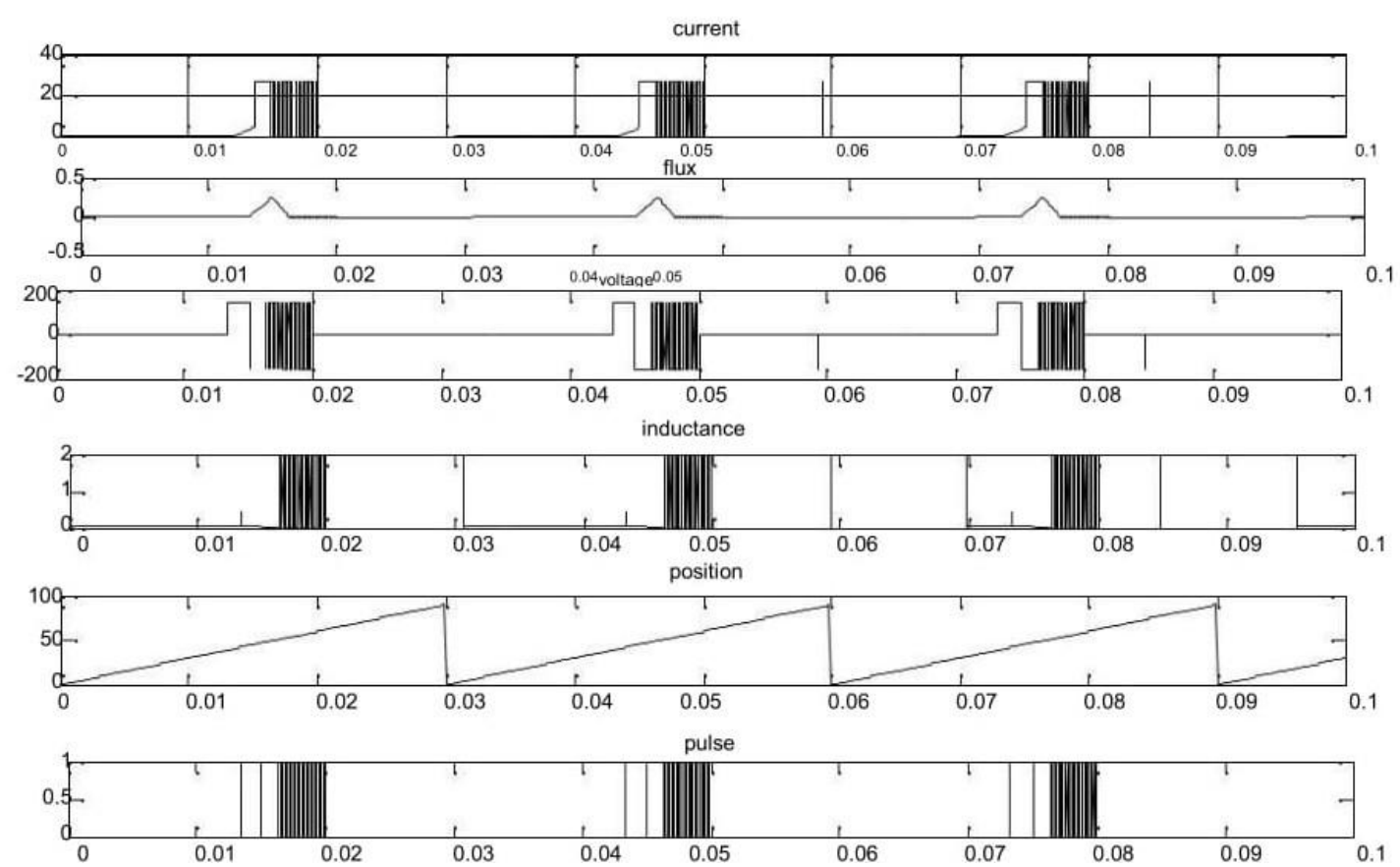

Figure 10. Current, flux, excitation voltage, inductance, position of rotor and firing pulse
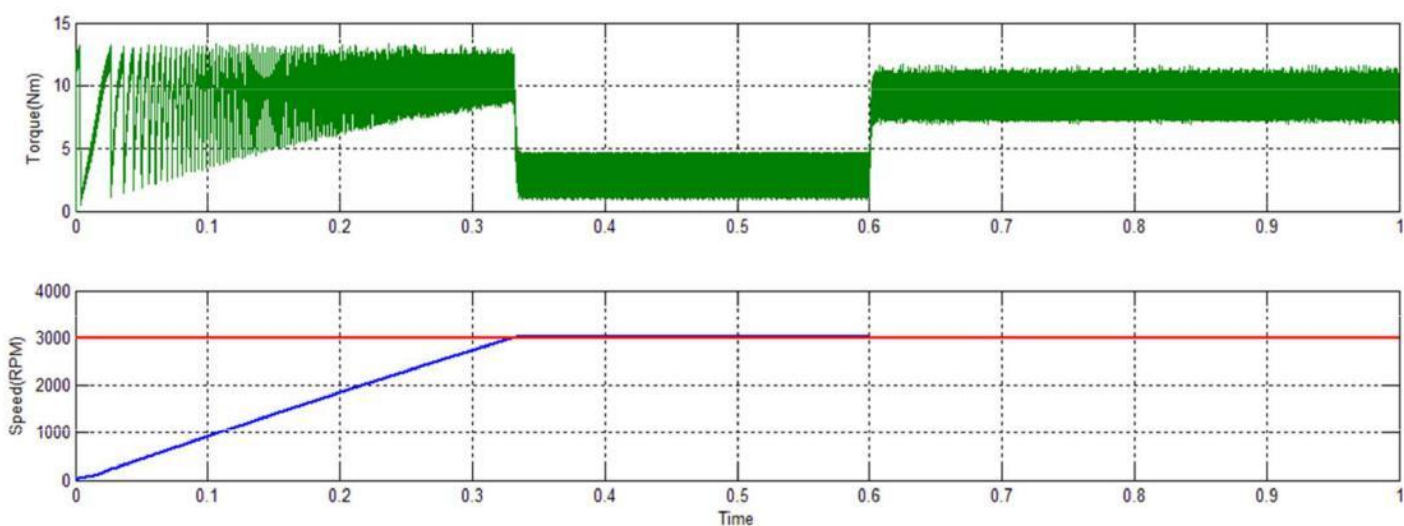

Figure 11. Speed and Torque performance of SRM motor 


\section{HARDWARE RESULT AND DISCUSSIONS}

The ANFIS controller and modified boost converter are employed to drive SRM motor is illustrated with functional block diagram in Figure 12. The motor speed is measured using encoder with rotor fed SRM motor. The actual speed and reference speed is compared to generate speed error processed through ANFIS controller. The voltage control decodes from position angle information of SRM motor to generate pulse for commutation schemes.

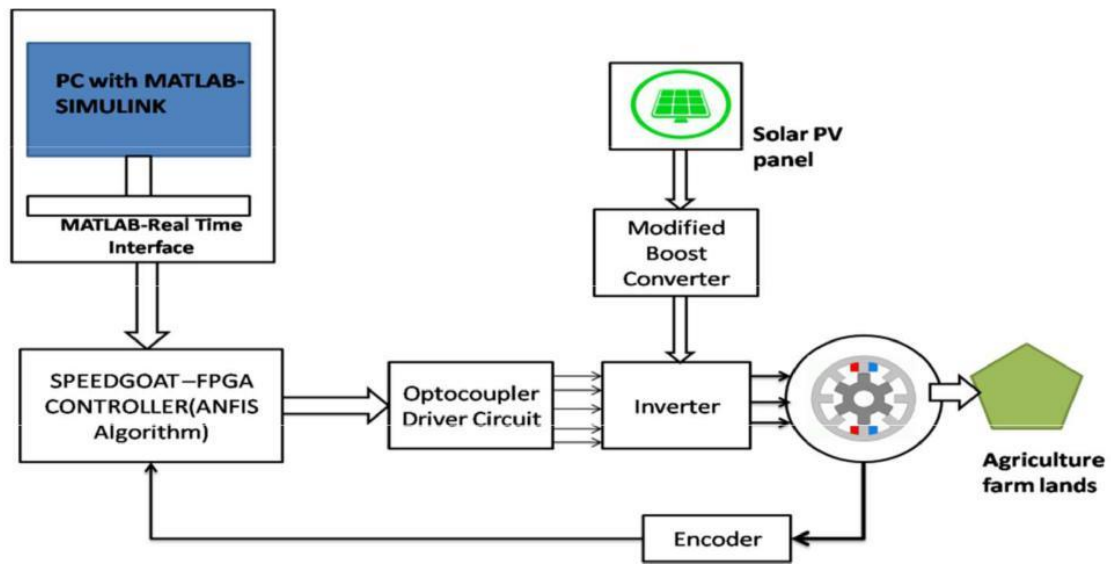

Figure 12. Functional Control Scheme of SRM motor drive

A prototype of SPV array fed C-dump converter based four phases, 8/6 poles SRM motor fed modified boost converter to verify the simulation results for developed actuation system. Several test results were conducted in the laboratory to evaluate performance of ANFIS controller for smart farm agriculture applications. ANFIS controller is trained with several iterations to improve speed control performance of motor actuation system. To test load performance of ANFIS controller and SPV array power generation, for emulating SPV array a lyton manufactured PV panel is setup in rooftop as shown in Figure 13. The proposed system with modified boost converter is constructed by using the IGBT module to boost PV voltage increase the input.

A real time SPEEDGOAT controller is used to control speed of SRM motor drive with PWM signals to drive semiconductor switches. Opto-couplers are proposed to provide isolation between speedgoat controller and gate drive circuit module. The shaft of SRM motor is employed with farm for smart agriculture actuation system as shown in Figure 14.

Figure 15(a) shows performance of SPV current (Ipv) and voltage (Vpv) for 24 volts input during mid time of 12 noon. A modified boost converter generates input PV and fed Vdc voltage to SRM motor drive. 


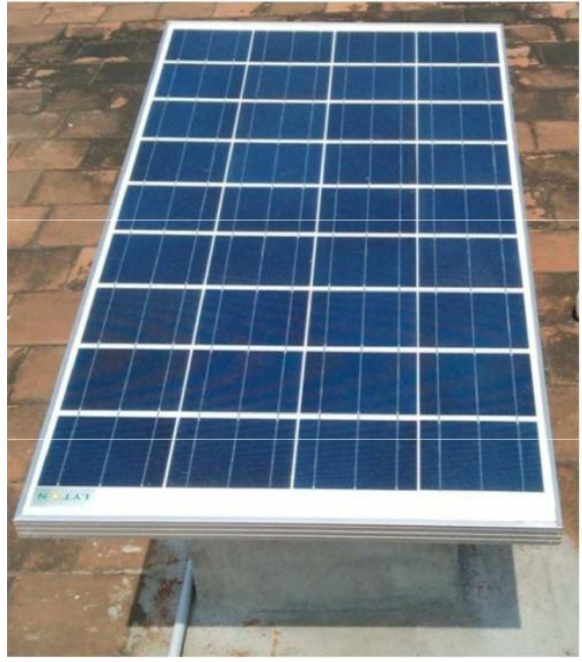

Figure 13. Rooftop solar PV system

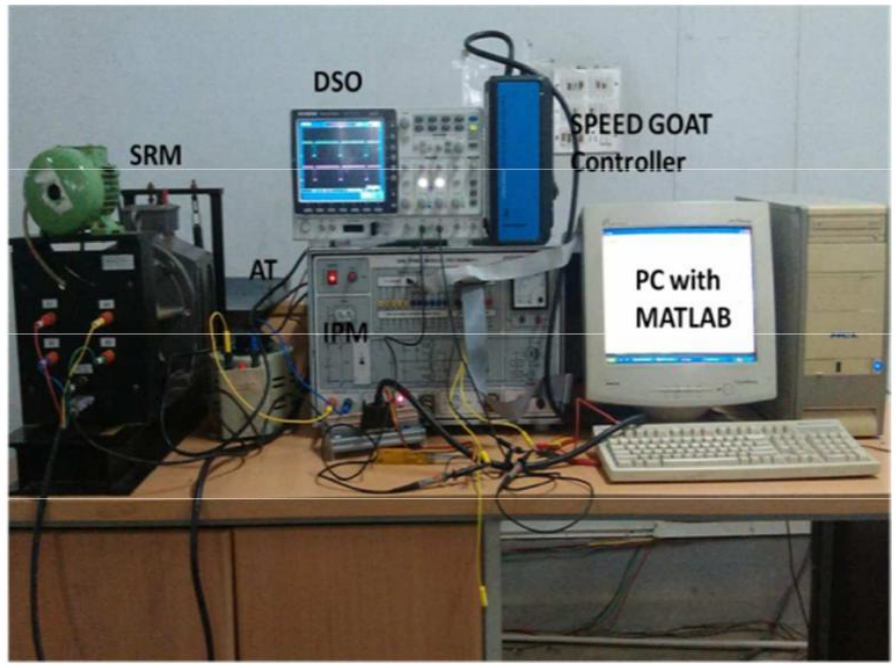

Figure 14. Laboratory hardware setup with SPEEDGOAT controller

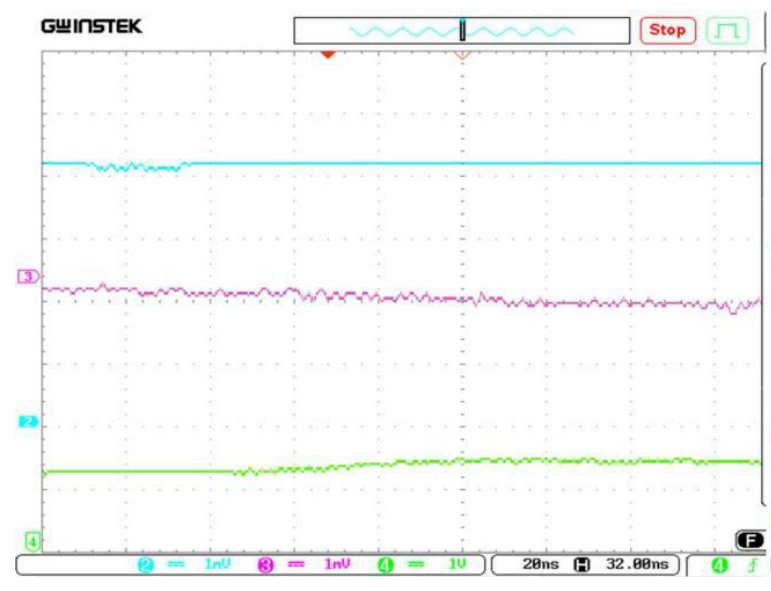

(a)

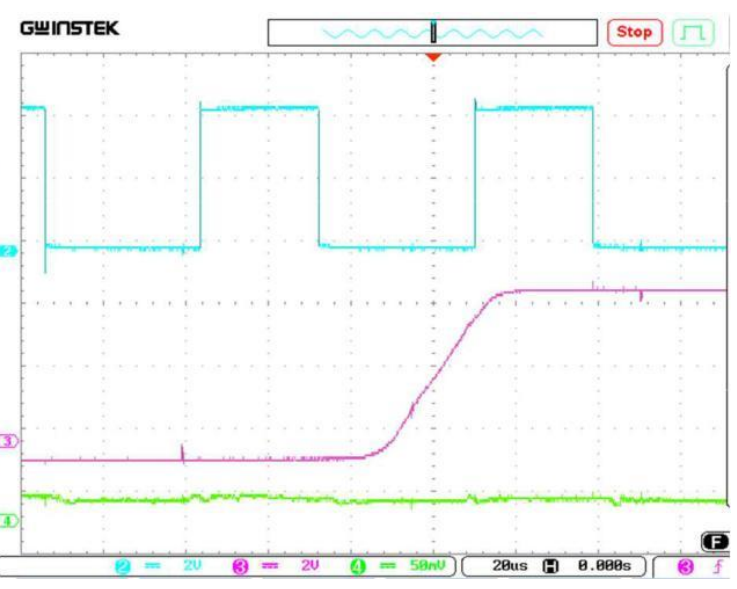

(b)

Figure 15(a-b). SPV array parameters and corresponding line voltage fed to modified boost converter with SRM motor drive system

At 12 noon SPV array feeding maximum voltage of 24 volts through rooftop solar as shown in Figure 15 (b) through modified boost converter a with PWM module to increase dc-link output voltage fed SRM motor drive. The small spikes in dc-link voltage are due switching transition of IGBT module fed c-dump SRM drive. The speed control of SRM motor is analyzed in SPEEDGOAT controller with real time simulation tools in MATLAB-PC. ANFIS controller simulated in external environment to acquire input sensor signal and fed control signals through optocoupler isolation. The PWM signals are to drive SRM motor for agriculture showering as shown in Figure 16(a) \& (b) which applied to IGBT driver module with reduced torque ripples as represented in Figure 17 shows output torque performance of SRM motor for ANFIS and fuzzy controller in which ANFIS has better performance with less ripples and increase flow of water towards agriculture and positioning all around agriculture area. 

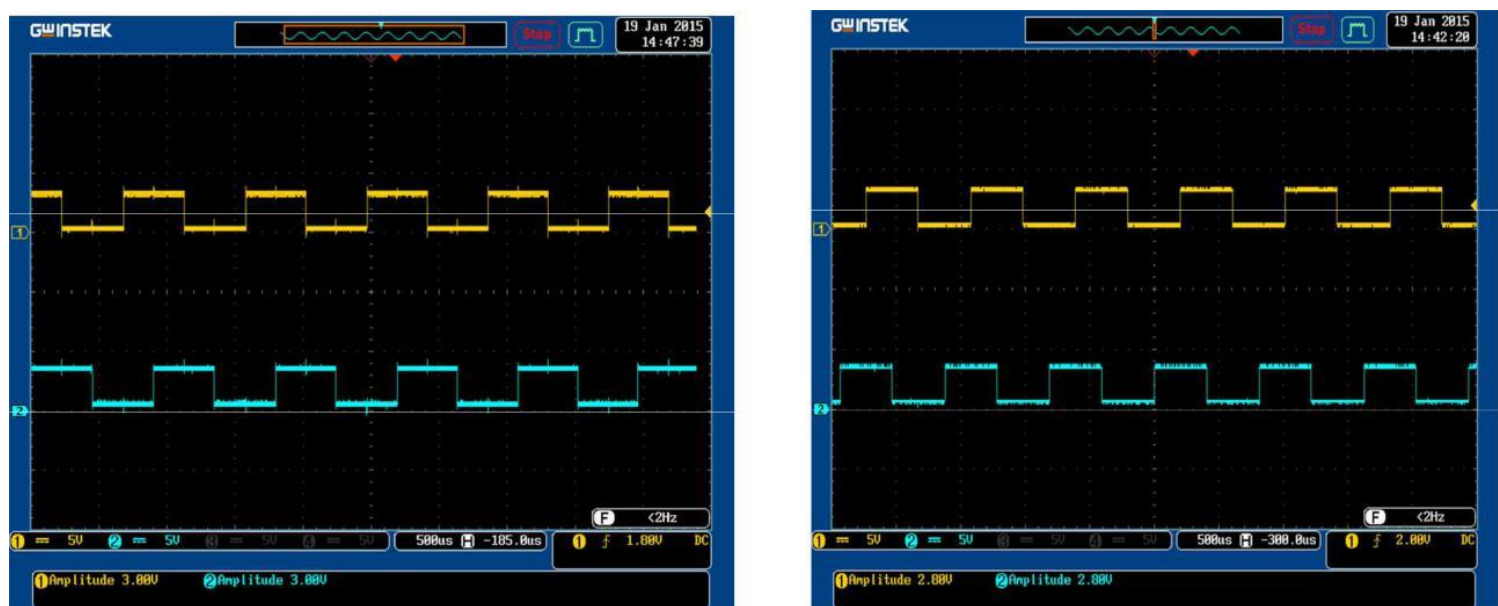

Figure 16 (a) \& (b). PWM 1-4 switching signals for SRM motor drive
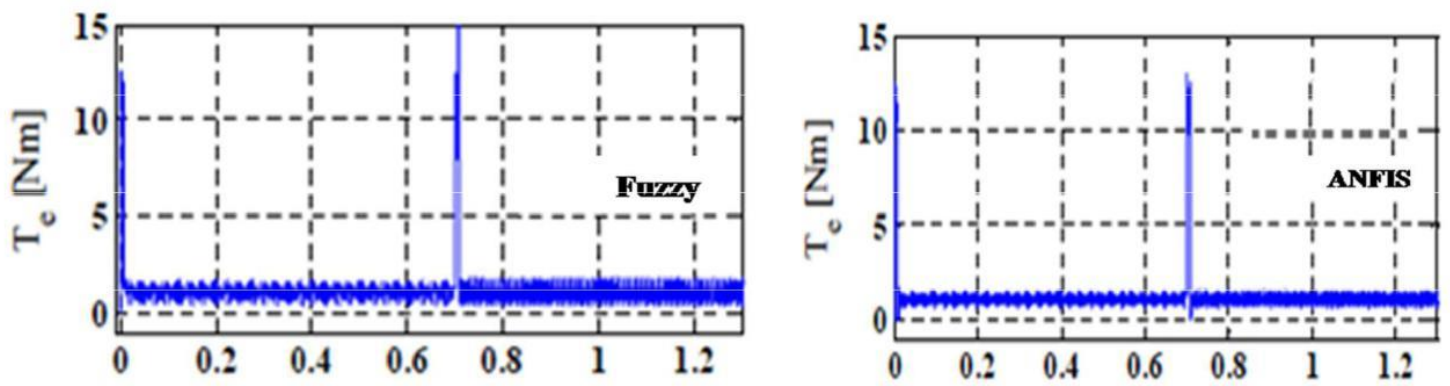

Figure 17. Real time simulation results for torque using fuzzy and ANFIS

Figure 18 demonstrates effectiveness of fuzzy controller in dynamic step behavior in closed speed control and effective flow water to smart fields and flowing in around places. Similar speed control test is conducted in Figure 19 with torque load of $0.1 \mathrm{Nm}$ as results confirm superiority of ANFIS controller. The speed of water flowing settles at 0.3 seconds compared with conventional controller observed through simulation while conventional controller takes 0.4. The control of speed by ANFIS algorithm is with fast dynamic response without less overshoot and zero steady state error.

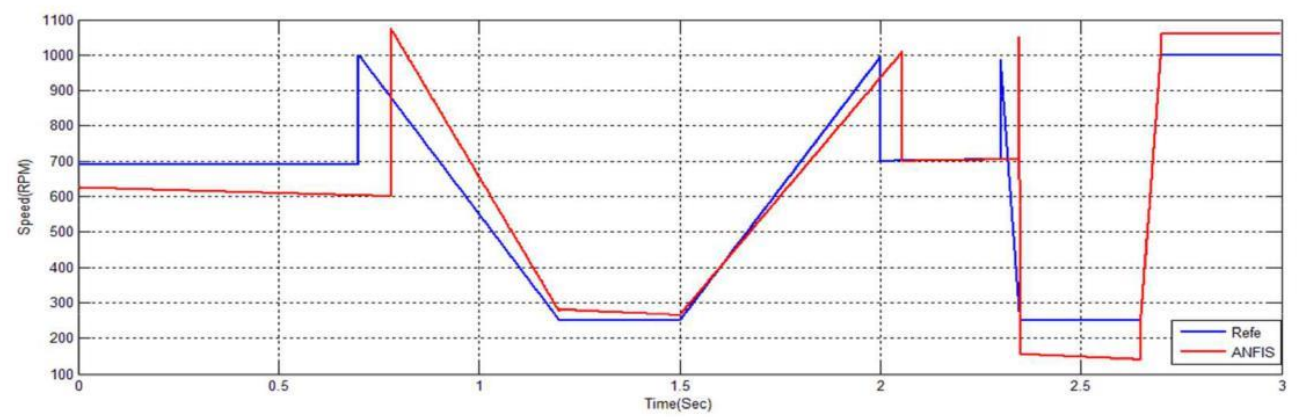

Figure 18. Speed Control responses for variable reference speed 

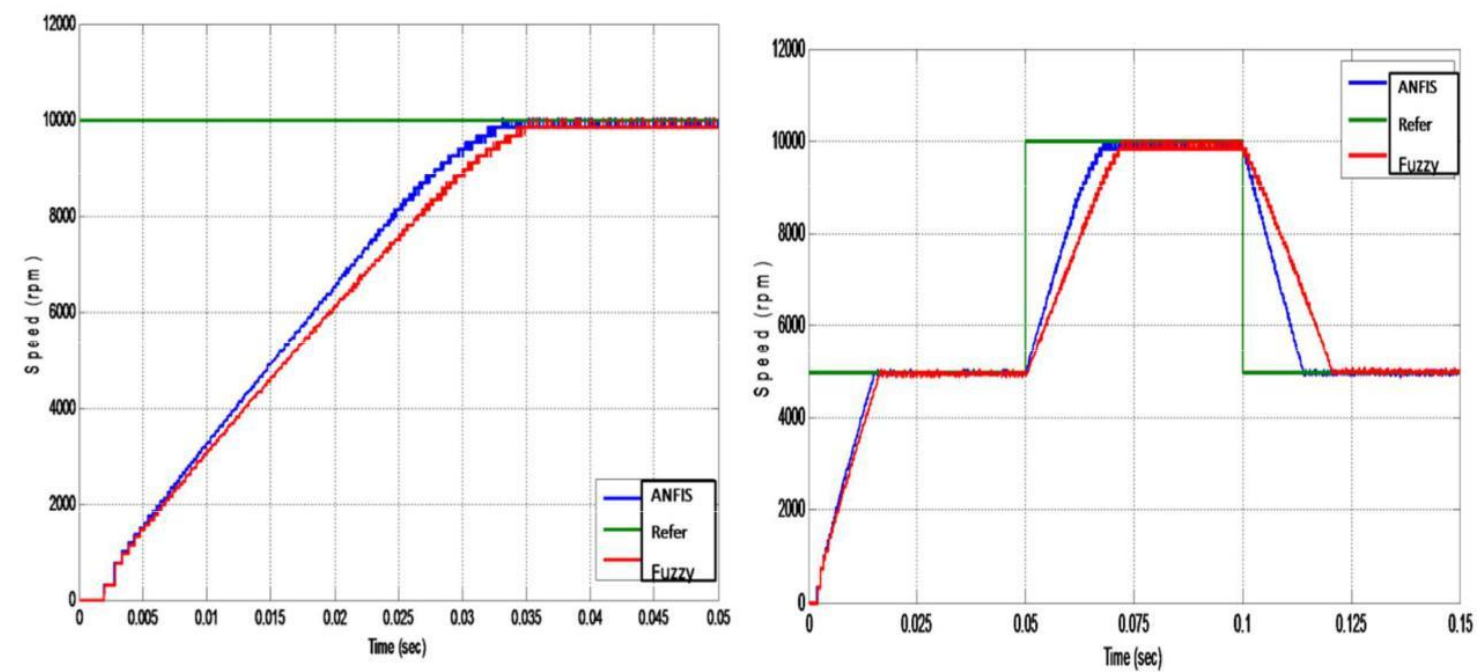

Figure 19. Dynamic behavior of SRM motor for fuzzy and ANFIS controller

\section{CONCLUSION}

SRM motor drive using ANFIS controller has been modeled in MATLABSIMULINK and validated with prototype solar PV driven power to modified boost converter. The real time is simulated using SPEEDGOAT hardware and the performance of proposed system is validated with trained data in ANFIS controller to match reference speed tracking. A modified boost converter is used for feeding dc-link voltage of SRM motor drive feeds through electronic commutation with reduced switching losses. The proposed converter is more compact with better power density stables output of PV voltage required to drive SRM motor actuation system. The ANFIS controller also reduces torque ripples of SRM motor which improves motor drive efficiency with reduction in rise time and error percent in overall system. Experimental and simulation results validates the proposed SRM motor with ANFIS controller for actuation system applications, further solar PV with modified boost converter employed good scalability for smart agriculture applications.

\section{REFERENCES}

1. B. Mangu, S. Akshatha, D. Suryanarayana and B. G. Fernandes, "Grid-Connected PVWind-Battery-Based Multi-Input Transformer-Coupled Bidirectional DC-DC Converter for Household Applications," inIEEE Journal of Emerging and Selected Topics in Power Electronics, Sept. 2016, vol. 4, no. 3, pp. 1086-1095.

2. B. Singh; A. K. Mishra; R. Kumar, Solar Powered Water Pumping System Employing Switched Reluctance Motor Drive,in IEEE Transactions on Industry Applications, vol.PP, no.99,2016, pp.1-1.

3. F. Peng, J. Ye and A. Emadi, "A Digital PWM Current Controller for Switched Reluctance Motor Drives," in IEEE Transactions on Power Electronics, vol. 31, no. 10, pp. 7087-7098, Oct. 2016.

4. Gobbi Ramasamy R. Vejian Rajandran Nirod Chandra Sahoo (2005), 'Modeling of Switched Reluctance Motor Drive System using Matlab/Simulink for Performance Analysis of Current Controllers" IEEE PEDS.

5. Jun Hang, You-rui Hung and Li Li (2010), 'Switched Reluctance Motor Direct Torque Control Research Based on RBF Neural network and Fuzzy Adaptive PID Controller', Second International conference on Intelligent Human-Machine System and Cybernetics.

6. Luis O. A. P. Henriques, Luis G. B. Rolim, Walter I. Suemitsu, Paulo J. C. Branco and Joaquim A. Dente(2000), 'Torque Ripple Minimization in a Switched Reluctance Drive by 
Neuro-Fuzzy Compensation', IEEE Transactions on Magnetics, Vol. 36, No. 5, pp. 3592 3594

7. Marcelo Gradella Villalva, Jonas Rafael Gazoli, and Ernesto Ruppert Filho , "Comprehensive Approach to Modeling and Simulation of Photovoltaic Arrays", IEEE Transactions on Power Electronics, vol 24, no. 5, 2009,pp 1198-1208.

8. Michael E. Ropp and Sigifredo Gonzalez "Development of a MATLAB/Simulink Model of a Single-Phase Grid-Connected Photovoltaic System" IEEE Transactions on Energy Conversion, 2005.

9. M. Alam, J. Jana and H. Saha, "Switched boost inverter applicable for solar photovoltaic system based micro-grid," 2016 2nd International Conference on Control, Instrumentation, Energy \& Communication (CIEC), Kolkata, 2016, pp. 422-426.

10. Murat AYAZ Ali Bekir YILDIZ (2006) 'An Equivalent Circuit Model for Switched Reluctance Motor', IEEE Transactions. Vol.40, No.3.

11. N. Skik and A. Abbou, Nonlinear control for MPPT and UPF of PV system connected to the grid, 2016 7th International Renewable Energy Congress (IREC), Hammamet, 2016, pp. 1-6.

12. P. García, C. A. García, L. M. Fernández, F. Llorens and F. Jurado, "ANFIS-Based Control of a Grid-Connected Hybrid System Integrating Renewable Energies, Hydrogen and Batteries," in IEEE Transactions on Industrial Informatics, vol. 10, no. 2, pp. 1107-1117, May 2014.

13. Rodrigues EMG, Melı' cio R, Mendes VMF, Catala o JPS. Simulation of a solar cell considering single-diode equivalent circuit model. In: International conference on renewable energies and power quality, Spain, 13-15 April, 2011.

14. Vladan.P.Vujieie (2012), 'Minimization of Torque Ripple and Copper losses in Switched Reluctance Drive', IEEE Transaction on Power Electronics Vol.27 No.1.

Received: August 18, 2016 Accepted: October 23, 2017 